\title{
Structural brain abnormalities in 12 persons with aniridia
}

\section{[version 1; peer review: 1 approved, 1 approved with}

\section{reservations]}

\author{
Madison K. Grant (iD) , Anastasia M. Bobilev2, Jordan E. Pierce33, Jon DeWitte4, \\ James D. Lauderdale ${ }^{1,2}$ \\ ${ }^{1}$ Department of Cellular Biology, University of Georgia, Athens, GA, 30602, USA \\ ${ }^{2}$ Neuroscience Division of the Biomedical and Health Sciences Institute, University of Georgia, Athens, GA, 30602, USA \\ ${ }^{3}$ Department of Psychology, University of Georgia, Athens, GA, 30602, USA \\ ${ }^{4}$ Athens Radiology Associates, Athens, GA, 30604, USA
}

V1 First published: 13 Mar 2017, 6:255

https://doi.org/10.12688/f1000research.11063.1

Latest published: 01 Sep 2017, 6:255

https://doi.org/10.12688/f1000research.11063.2

\section{Abstract}

Background: Aniridia is a disorder predominately caused by heterozygous loss-of-function mutations of the PAX6 gene, which is a transcriptional regulator necessary for normal eye and brain development. The ocular abnormalities of aniridia have been well characterized, but mounting evidence has implicated brain-related phenotypes as a prominent feature of this disorder as well. Investigations using neuroimaging in aniridia patients have shown reductions in discrete brain structures and changes in global grey and white matter. However, limited sample sizes and substantive heterogeneity of structural phenotypes in the brain remain a challenge. Methods: Here, we examined brain structure in a new population sample in an effort to add to the collective understanding of anatomical abnormalities in aniridia. The current study used 3T magnetic resonance imaging to acquire high-resolution structural data in 12 persons with aniridia and 12 healthy demographically matched comparison subjects. Results: We examined five major structures: the anterior commissure, the posterior commissure, the pineal gland, the corpus callosum, and the optic chiasm. The most consistent reductions were found in the anterior commissure and the pineal gland; however, abnormalities in all of other structures examined were present in at least one individual. Conclusions: Our results indicate that the anatomical abnormalities in aniridia are variable and largely individual-specific. These findings suggest that future studies investigate this heterogeneity further, and that normal population variation should be considered when evaluating structural abnormalities.

\section{Open Peer Review}

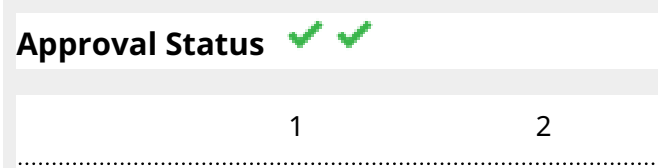

version 2

(revision)

01 Sep 2017

version 1

13 Mar 2017

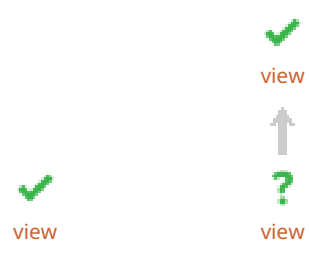

1. Veronica van Heyningen, University College London, London, UK

2. Lutz Jäncke ID, University of Zurich, Zurich,

Switzerland

Any reports and responses or comments on the article can be found at the end of the article. 
Keywords

MRI, PAX6, neuroanatomy

Corresponding author: James D. Lauderdale (jdlauder@uga.edu)

Competing interests: No competing interests were disclosed.

Grant information: This research was supported by a grant from the Sharon Stewart Aniridia Research Trust to AMB and JDL.

The funders had no role in study design, data collection and analysis, decision to publish, or preparation of the manuscript.

Copyright: (c) 2017 Grant MK et al. This is an open access article distributed under the terms of the Creative Commons Attribution License, which permits unrestricted use, distribution, and reproduction in any medium, provided the original work is properly cited. Data associated with the article are available under the terms of the Creative Commons Zero "No rights reserved" data waiver (CC0 1.0 Public domain dedication).

How to cite this article: Grant MK, Bobilev AM, Pierce JE et al. Structural brain abnormalities in 12 persons with aniridia [version 1; peer review: 1 approved, 1 approved with reservations] F1000Research 2017, 6:255 https://doi.org/10.12688/f1000research.11063.1

First published: 13 Mar 2017, 6:255 https://doi.org/10.12688/f1000research.11063.1 


\section{Introduction}

Aniridia is panocular, congenital, and progressive disorder with an occurrence of approximately 1 in 83,000 live births ${ }^{1,2}$. Aniridia is best characterized by the lack of or hypoplasia of the iris (for which it is named), in addition to several other ocular abnormalities, which culminate in reduced visual acuity ${ }^{3}$. Due to the progressive nature of the disease, individuals usually develop multiple ocular abnormalities, such as keratopathy, corneal vascularization and opacification, glaucoma, anterior chamber fibrosis, and cataracts ${ }^{4-7}$. Although aniridia is most well known for its ocular phenotypes, the condition has a number of other abnormalities, including sensory, neural, cognitive, and auditory processing abnormalities ${ }^{8,9}$.

The development of aniridia in humans is linked to heterozygous loss-of-function mutations to the PAX6 gene, which encodes a highly conserved transcription factor critical for normal eye and neural development ${ }^{1}$. The vast majority of aniridia cases $(80 \%)$ are associated with mutations in $P A X 6^{2,10}$. Functional mutations in this gene can be either sporadic or familial, and causal mutations in aniridia encompass a large number of variants. The majority of these variants are single nucleotide polymorphisms, which lead to a premature termination codon, and are found across the PAX6 locus ${ }^{10,11}$. PAX6 is expressed in the developing eye, brain, and spinal cord, and is required for aspects of anatomical and functional development of the central nervous system (CNS) and visual system $^{12}$. Within the CNS, PAX6 is involved in patterning, regionalization, and the formation of neural circuits ${ }^{13-16}$. Previous studies of patients with aniridia using structural magnetic resonance imaging (MRI) have shown abnormalities in major fiber tracts and subcortical structures of the brain, including the anterior commissure $^{9,17-20}$, posterior commissure ${ }^{18,20}$, corpus callosum ${ }^{9,19,20}$, pineal gland ${ }^{18,20}$, optic chiasm ${ }^{20}$, and olfactory bulb ${ }^{17,18}$. The most consistently reported abnormalities are found in the anterior commissure, pineal gland, and optic chiasm; abnormalities in the posterior commissure, corpus callosum, and olfactory bulb are found in fewer than $35 \%$ of patients examined. Additionally, studies have shown conflicting results regarding grey matter volume differences in aniridia, with reports of both increases and decreases in whole brain grey matter ${ }^{21,22}$. Most recently, it has been shown that there is an accelerated age-related increase in cortical thinning of the inferior parietal lobe and prefrontal/premotor areas in both brain hemispheres in aniridia compared to healthy patients ${ }^{23}$.

While several previous studies have investigated structural brain abnormalities in patients with aniridia, the variance in brain structures affected and extent of anatomical abnormalities is high. The variance observed in the published literature may be interpreted as a result of genetic differences in patient samples, either directly related to disease-causing mutations or modifier effects caused by genomic differences across subjects. The current study sought to investigate gross anatomical correlates of aniridia in a new population sample. Results from this study will serve as a comparison for previous studies, as well as contribute to what is known about the distribution of neuroanatomical phenotypes in the aniridia population as a whole.

\section{Methods}

\section{Subjects}

A total of 14 individuals with aniridia and 15 healthy comparison individuals participated in the current study. Data from two participants with aniridia were excluded from analyses (due to a significant artifact and missing data). One healthy subject was excluded due to an anatomical abnormality, and two others were excluded because they did not match the demographic profile of an individual in the aniridia group included in the analysis. The remaining 12 individuals with aniridia ( 7 females; mean age $=36$ years, $\mathrm{SD}=15)$ and 12 age- and gender-matched comparisons (7 females; mean age $=35$ years, $S D=14$ ) were included in the analyses (Table 1). Healthy comparison subjects were recruited through flyers posted in the community. Participants with aniridia were recruited through the Aniridia Foundation International Conference held in 2011 in Athens, Georgia and had been clinically diagnosed with aniridia. Exonic sequencing of the PAX6 gene (11p13) (OMIM: 607108) was conducted at the University of Georgia, as previously described ${ }^{10,24}$. All mutations, which can be found in Table 1, have been submitted to the Human PAX6 Allelic Variant Database (http://lsdb.hgu.mrc.ac.uk/home.php?select_ $\mathrm{db}=\mathrm{PAX} 6$ ), as part of a previous genotype identification study ${ }^{10}$. Three of the participants with aniridia belonged to the same family, and all other participants included in the analyses were unrelated. After written informed consent was obtained and MRI safety screening was conducted, all participants completed an MRI session in which a high-resolution structural scan was obtained. The Institutional Review Board of the University of Georgia approved all activities prior to subject recruitment, data collection, and data analysis (project number: 2011-10862-1; STUDY00003122).

\section{MRI data acquisition}

All data were collected on a 3T GE Signa MRI (General Electric, Milwaukee, WI, USA) at the University of Georgia's Bio-Imaging Research Center. To obtain a high-resolution structural scan, images were acquired with a T1-weighted 3D FSPGR sequence [echo time $(\mathrm{TE})=\mathrm{min}$ full, flip angle $=20^{\circ}$; field of view $(\mathrm{FOV})=240$ $\mathrm{mm} \times 240 \mathrm{~mm}$; matrix size $=256 \times 256,150$ axial slices; in-slice resolution $=0.94 \times 0.94 \mathrm{~mm}$; slice thickness $=1.2 \mathrm{~mm}]$.

\section{$\mathrm{MRI}$ data analysis}

MR images were transferred to a DICOM image format and analyzed using two software programs, SPM run on MATLAB and OsiriX. For SPM analysis, DICOM files were converted to nifti format and analyzed using Statistical Parametric Mapping Software (SPM8; Wellcome Trust Centre for Neuroimaging; http://www.fil. ion.ucl.ac.uk/spm/) run on a MATLAB software platform (MATLAB Release 2015b; The Mathworks, Inc., Natick, MA, USA). SPM software was used to compare aniridia subjects to their demographically matched comparison subjects. DICOM files were additionally analyzed using Osirix Lite DICOM viewer (OsiriX v5.6; Pixmeo SARL, Bernex, Switzerland) and all figures generated using this software. All 24 individual subjects' data were visually inspected for gross anatomical abnormalities in two independent sessions by the first author (MG) and a radiologist (JDW). The radiologist was completely blinded to patient genotype when examining the MRI 
scans. This study focused on evaluating five major brain structures: anterior commissure, posterior commissure, pineal gland, corpus callosum, and optic chiasm.

\section{Results}

Whole brain analysis was used to identify major structural abnormalities in aniridia patients. All neuroanatomical results are reported in Table 1, which includes subject demographics and mutations. We analysed five major brain structures that demonstrate clear anatomical abnormalities in aniridia patients. Our study showed that all 12 aniridia patients had a reduced anterior commissure when compared to their demographically matched healthy comparisons, as shown in Figure 1. The posterior commissure was reduced in 5/12 aniridia patients and normal in $7 / 12$ of aniridia patients (Figure 1). Of the five aniridia patients with reduced posterior commissures, one had a reduced commissure at the midline. The pineal gland was affected in all 12 aniridia patients: absent in two (Figure 1), highly reduced in one, and reduced in nine. The corpus callosum was slightly thinned in $3 / 12$ aniridia patients and normal in 9/12 aniridia patients (Figure 2). The optic chiasm was reduced in $7 / 12$ of patients (Figure 2) and normal in $5 / 12$ patients.

In an effort to consider normal structural variation in the healthy population, we also evaluated healthy comparisons for structural brain abnormalities. We saw a reduced anterior
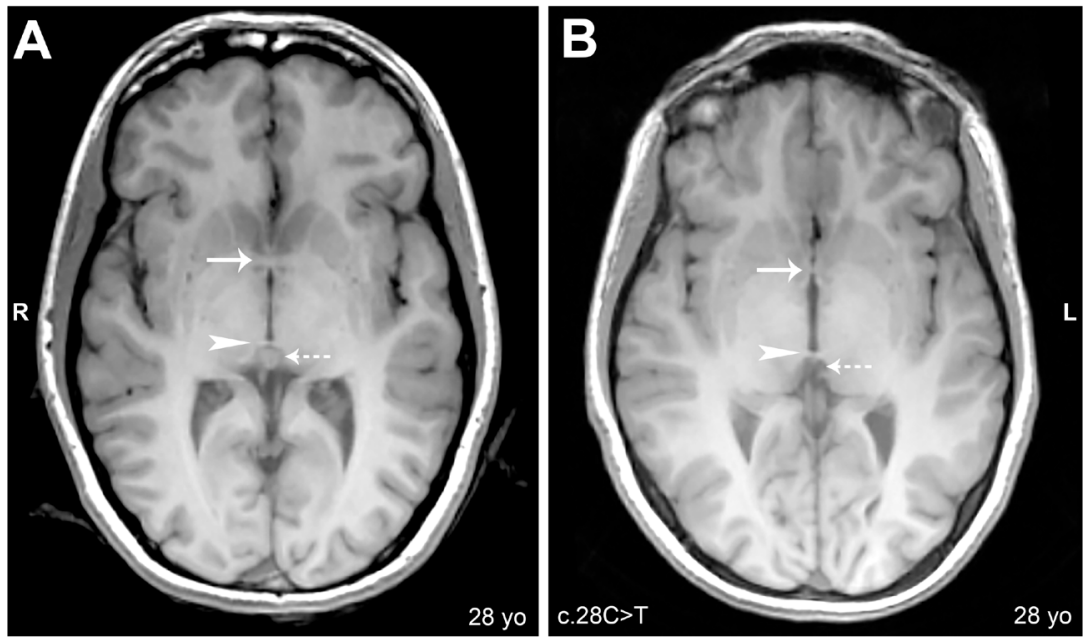

Figure 1. Anterior commissure, posterior commissure, and pineal gland: Axial cerebral T1-weighted magnetic resonance images, slice thickness 1.2mm. (A) Subject 12C: Arrow shows normal anterior commissure; arrowhead shows normal posterior commissure; dashed arrow shows normal pineal gland. (B) Subject 12A: Arrow shows reduced anterior commissure; arrowhead shows normal posterior commissure; dashed arrow shows absence of pineal gland.
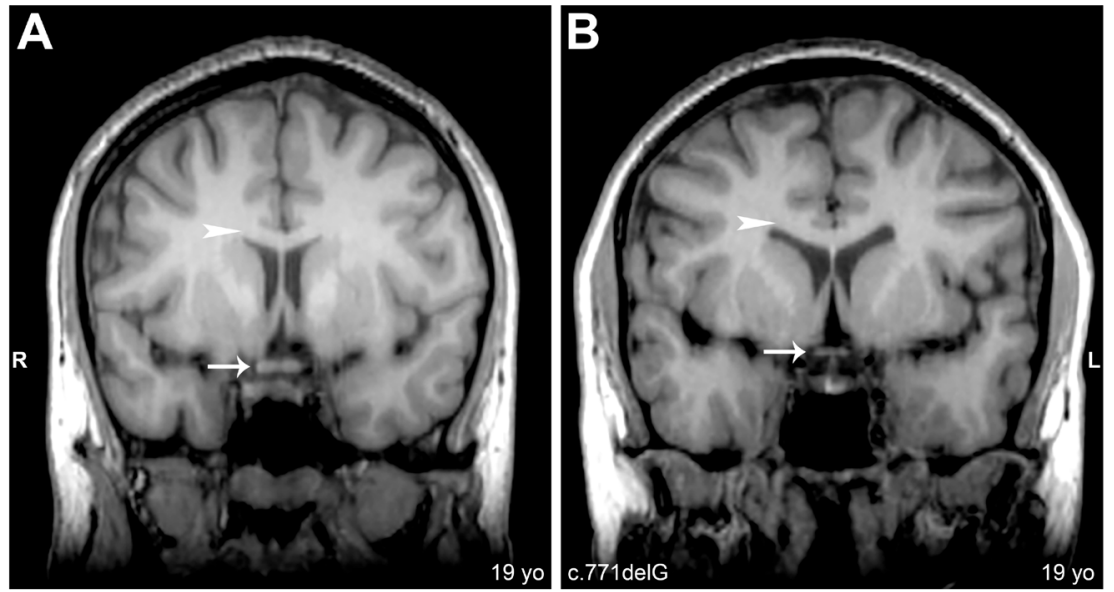

Figure 2. Optic chiasm and corpus callosum: Coronal cerebral T1-weighted magnetic resonance images, slice thickness $1.2 \mathrm{~mm}$. (A) Subject 2C: Arrow shows normal optic chiasm. (B) Subject 2A: Arrow shows reduced optic chiasm. Arrowheads in A and B denote normal corpus callosum. 
commissure in two of the healthy comparisons and a reduced posterior commissure in one healthy comparison. The pineal gland showed the most variance within the healthy comparison group with one subject with no visible pineal gland, three healthy comparisons with slightly reduced to reduced pineal glands, and eight healthy comparisons with normal pineal glands. All healthy comparisons had normal corpus callosums and optic chiasms. A full description of which structures showed abnormalities in both the aniridia and healthy comparison groups are reported in Table 1. These findings provide context for asserting disease-related changes in the aniridia population, in the current study as well as others.

Table 1. Subject demographics and structural abnormalities as seen in structural magnetic resonance

images. Gender, age, mutation, and structural abnormalities of both aniridia subjects and healthy comparisons. Subject ID: Numbers are matched subjects, A refers to aniridia subjects, C refers to healthy comparisons. ND, not determined.

\begin{tabular}{|c|c|c|c|c|c|c|c|c|}
\hline \multicolumn{9}{|c|}{ ANIRIDIA } \\
\hline $\begin{array}{l}\text { Subject } \\
\text { ID }\end{array}$ & Gender & Age & Mutation & $\begin{array}{c}\text { Anterior } \\
\text { commissure }\end{array}$ & $\begin{array}{l}\text { Posterior } \\
\text { commissure }\end{array}$ & $\begin{array}{l}\text { Pineal } \\
\text { gland }\end{array}$ & $\begin{array}{l}\text { Corpus } \\
\text { callosum }\end{array}$ & $\begin{array}{l}\text { Optic } \\
\text { chiasm }\end{array}$ \\
\hline $1 \mathrm{~A}$ & Male & 38 & c. $482 \mathrm{delG}$ & Reduced & Normal & Reduced & Normal & Normal \\
\hline $2 \mathrm{~A}$ & Female & 19 & c. $771 \mathrm{delG}$ & Reduced & Normal & Reduced & $\begin{array}{l}\text { Slightly } \\
\text { reduced }\end{array}$ & Reduced \\
\hline $3 \mathrm{~A}$ & Male & 18 & c. $949 \mathrm{C}>\mathrm{T}$ & Reduced & Normal & Reduced & Normal & Reduced \\
\hline $4 \mathrm{~A}$ & Male & 47 & ND & Reduced & Normal & Reduced & Normal & Normal \\
\hline $5 A$ & Female & 53 & ND & Reduced & Reduced & Reduced & Normal & Normal \\
\hline $6 \mathrm{~A}$ & Male & 46 & c.204delC & Reduced & Normal & Reduced & Normal & Reduced \\
\hline $7 \mathrm{~A}$ & Female & 24 & c.204delC & Reduced & Reduced & Reduced & Normal & Reduced \\
\hline $8 \mathrm{~A}$ & Female & 25 & ND & Reduced & $\begin{array}{l}\text { Reduced } \\
\text { center }\end{array}$ & $\begin{array}{l}\text { Highly } \\
\text { reduced }\end{array}$ & Normal & Reduced \\
\hline $9 \mathrm{~A}$ & Female & 51 & c. $766-3 C>G$ & Reduced & Reduced & Absent & Normal & Normal \\
\hline $10 \mathrm{~A}$ & Female & 60 & c. $799 A>T$ & Reduced & Reduced & Reduced & $\begin{array}{l}\text { Slightly } \\
\text { reduced }\end{array}$ & Reduced \\
\hline $11 \mathrm{~A}$ & Male & 20 & c.204delC & Reduced & Normal & Reduced & Normal & Reduced \\
\hline $12 \mathrm{~A}$ & Female & 28 & c. $28 \mathrm{C}>\mathrm{T}$ & Reduced & Normal & Absent & $\begin{array}{l}\text { Slightly } \\
\text { reduced }\end{array}$ & Normal \\
\hline
\end{tabular}

\begin{tabular}{|c|c|c|c|c|c|c|c|c|}
\hline $\begin{array}{c}\text { PAX6 NORMAL } \\
\text { Subject } \\
\text { ID }\end{array}$ & Gender & Age & Mutation & $\begin{array}{c}\text { Anterior } \\
\text { commissure }\end{array}$ & $\begin{array}{c}\text { Posterior } \\
\text { commissure }\end{array}$ & $\begin{array}{c}\text { Pineal } \\
\text { gland }\end{array}$ & $\begin{array}{c}\text { Corpus } \\
\text { callosum }\end{array}$ & $\begin{array}{c}\text { Optic } \\
\text { chiasm }\end{array}$ \\
\hline $1 C$ & Male & 37 & PAX6 Normal & Normal & Normal & Normal & Normal & Normal \\
\hline $2 \mathrm{C}$ & Female & 20 & PAX6 Normal & Normal & Normal & Normal & Normal & Normal \\
\hline $3 \mathrm{C}$ & Male & 18 & PAX6 Normal & Normal & Normal & Normal & Normal & Normal \\
\hline $4 \mathrm{C}$ & Male & 50 & PAX6 Normal & Normal & Normal & Normal & Normal & Normal \\
\hline $5 \mathrm{C}$ & Female & 51 & PAX6 Normal & Normal & Normal & Reduced & Normal & Normal \\
\hline $6 \mathrm{C}$ & Male & 50 & PAX6 Normal & Reduced & Normal & Normal & Normal & Normal \\
\hline $7 \mathrm{C}$ & Female & 22 & PAX6 Normal & Normal & Normal & Normal & Normal & Normal \\
\hline $8 \mathrm{C}$ & Female & 23 & PAX6 Normal & Normal & Normal & Normal & Normal & Normal \\
\hline $9 \mathrm{C}$ & Female & 48 & PAX6 Normal & Reduced & Reduced & Absent & Normal & Normal \\
\hline $10 \mathrm{C}$ & Female & 56 & PAX6 Normal & Normal & Normal & Reduced & Normal & Normal \\
\hline $11 \mathrm{C}$ & Male & 21 & PAX6 Normal & Normal & Normal & $\begin{array}{c}\text { Slightly } \\
\text { reduced }\end{array}$ & Normal & Normal \\
\hline $12 \mathrm{C}$ & Female & 28 & PAX6 Normal & Normal & Normal & Normal & Normal & Normal \\
\hline
\end{tabular}




\section{Dataset 1. Aniridia and healthy comparison MRI data}

http://dx.doi.org/10.5256/f1000research.11063.d153799

Structural MRI DICOM files for 12 aniridia and 12 healthy comparison individuals. Files are in DICOM format and labeled according to subject I.D. found in Table 1. These files can be opened using SPM software run in Matlab or OsiriX DICOM viewer (see Methods section)

\section{Discussion}

The most commonly reported neuroanatomical abnormality in MRI studies of aniridia patients is the anterior commissure. Previous studies have reported changes in the anterior commissure with some cases described as reductions and others reported as complete absence of the structure ${ }^{9,17-19}$. Consistent with these reports, our study identified a reduction in the anterior commissure in all 12 aniridia patients, but none of the patients lacked the structure. The posterior commissure has also been evaluated in previous studies: one study reports that it is present in all subjects while the other study presented evidence that one patient had an absent structure while the others had normal posterior commissures ${ }^{18,20}$. We found no individuals lacking the posterior commissure, and fewer than half of our aniridia patients seemed to have an abnormal structure. Interestingly though, it seems as if one patient exhibited a reduction of the posterior commissure at the midline with thickened bundles adjacent to the midline suggesting that commissure formation was incomplete. PAX6 has a known role in formation of the posterior commissure in rodents, so it is likely that this phenotype in humans is a direct consequence of PAX6 deficiency ${ }^{15}$. In agreement with previous findings, we also see abnormal or absent pineal glands in our entire patient population. This finding is consistent with sleep regulation deficits in persons with aniridia reported in other studies ${ }^{25}$. The corpus callosum has also been a structure commonly evaluated in aniridia MRI studies, with many reporting reductions in corpus callosum thickness and severe agenesis ${ }^{9,19,20}$. However, we found very few patients present with a reduced or abnormal corpus callosum, and propose that the slight reduction we see in three of our patients falls within normal population variation. Unlike most previous studies, we examined the optic chiasm, and found a reduction in the structure in more than half of our patients. This reduction could be a developmental consequence of the disorder or a progressive phenotype associated with reduced levels of PAX6. Anatomical abnormality findings seem to be highly dependent on population sample, and a larger collective sample in the literature will help us get closer to understanding common disease traits and variation.

As described above, we observed a reduction in the anterior commissure in every patient we evaluated and a reduction of the posterior commissure in five patients, but no individuals completely lacked either structure. Our study utilized a high resolution 3T MRI for data acquisition, while most other studies used a 1.5T MRI. Signal to noise ratio from 3T MRIs are almost double that of $1.5 \mathrm{~T}$ MRIs, which will lead to an improved image quality and resolution from the $3 \mathrm{~T}$ magnet ${ }^{26}$. We propose that the difference in observing a reduced versus absent anterior/posterior commissure may be due to a difference in scan resolution between images captured from a $3 \mathrm{~T}$ versus $1.5 \mathrm{~T}$ magnet. We see multiple patients in our group who have a severely reduced anterior commissure, and identifying this abnormality using a $1.5 \mathrm{~T}$ magnet may be more difficult than when using a 3T. Additionally, the posterior commissure is smaller than the anterior commissure naturally, making it more difficult to distinguish between presence and absence in a scan. Lower scan resolution may not capture small structures such as these commissures, especially if they are reduced in size, leading to a false judgment of their absence.

A recent study has found an age component to cortical thickness in aniridia patients when compared to healthy individuals. The study found that in patients with aniridia there is an accelerated reduction in cortical thickness of the inferior parietal lobe and prefrontal/premotor areas in both brain hemispheres ${ }^{23}$. Adding to this age component seen in the Yogarajah (2016) study, there are also population differences in brain anatomy, even within healthy groups, between younger subjects and older subjects ${ }^{27}$. Additionally, as we show in our study, there are anatomical abnormalities even within healthy, unaffected participants. This makes it vitally important for careful selection of comparison subjects, and presents a caveat for interpreting differences we see in this and other clinical populations.

In addition to abnormal structural findings in patient populations with aniridia, multiple studies have assessed volumetric differences in grey and white matter in the brains of aniridia versus healthy comparisons. Similar to the findings in gross structural differences, much variation exists between reports. Some studies show an increase in grey matter volume in aniridia patients compared to healthy control groups, while others find both increases and decreases depending on brain region ${ }^{21,22}$. Changes in white matter findings follow the same suit with some reports of reductions in white matter and others finding both reductions and increases ${ }^{21,22}$. Even more interestingly, structures, such as the anterior commissure, posterior commissure, and pineal gland, show no deviation from healthy in these group-wise comparisons. This suggests that either the abnormalities seen in these structures are not as common among aniridia patients as previously thought, or that the characteristics of anatomical changes observed in aniridia patients have a high degree of variability within the population. Due to the consistency of abnormalities in structures like the anterior commissure in our study, as well as others, we predict the latter explains this discrepancy.

\section{Conclusions}

The current study investigated anatomical brain abnormalities correlated to aniridia in a new population sample in an effort to serve as a comparison to previous studies. Our aim was to contribute to what is known about the distribution of neuroanatomical phenotypes in the aniridia population as a whole. Although we found similar neuroanatomical abnormalities as previous studies, we find the severity is not as great as previously reported. The anterior commissure and pineal gland seem to be the structures most affected in the aniridia patients we examined, and we do see abnormalities in the posterior commissure, corpus callosum and the optic chiasm, albeit at lower frequency than previously reported. We believe the neuroanatomical abnormalities seen in aniridia populations have a high level of variability, and future studies should be aimed at collecting more patient MRI scans so that the breadth of abnormalities can be assessed. 


\section{Ethical approval and consent}

MRI sessions were completed after written informed consent was obtained and MRI safety screening was completed. All activities were approved by the Institutional Review Board of the University of Georgia prior to subject recruitment and data collection. All individuals who participated in this study provided consent for their demographic, mutation information, and images to be published.

\section{Data availability}

Dataset 1: Aniridia and healthy comparison MRI data: Structural MRI DICOM files for 12 aniridia and 12 healthy comparison individuals. Files are in DICOM format and labeled according to subject I.D. found in Table 1. These files can be opened using SPM software run in Matlab or OsiriX DICOM viewer (see Methods section). doi, 10.5256/f1000research.11063.d15379928

Mutation information that has been presented here is also available through PAX6 Allelic Variant Database (http://lsdb.hgu.mrc.ac.uk/ home.php?select_db=PAX6).

\section{Author contributions}

AMB and JDL conceived this study as part of a large neuroimaging effort in this clinical population. JEP provided technical expertise on MRI imaging and data acquisition, and assisted AMB with experimental design and data collection. MKG analyzed the data first followed by JDW, who analyzed the data second (independently) to determine structural abnormalities in each brain. MKG and AMB prepared the first draft of the manuscript. All authors were involved in the revisions of the draft manuscript and have agreed to the final content.

\section{Competing interests}

No competing interests were disclosed.

\section{Grant information}

This research was supported by a grant from the Sharon Stewart Aniridia Research Trust to AMB and JDL.

The funders had no role in study design, data collection and analysis, decision to publish, or preparation of the manuscript.

\section{Acknowledgements}

AMB is a Franklin Foundation Neuroimaging Fellow and an ARCS Scholar.

Collection of magnetic resonance imaging data was made possible by the University of Georgia Bioimaging Research Center. The authors wish to thank Ms. Kimberly Mason for her assistance with data collection and subject screening, Ms. Jill Nerby, Director and Founder of Aniridia Foundation International, and the participants in this study for their support of this research.
1. Hanson IM, Seawright A, Hardman K, et al.: PAX6 mutations in aniridia. Hum $\mathrm{Mol}$ Genet. 1993; 2(7): 915-920 PubMed Abstract | Publisher Full Text

2. Grønskov K, Olsen JH, Sand A, et al:: Population-based risk estimates of Wilms tumor in sporadic aniridia. A comprehensive mutation screening procedure of PAX6 identifies $80 \%$ of mutations in aniridia. Hum Genet. 2001; 109(1): 11-18. PubMed Abstract | Publisher Full Text

3. Nelson LB, Spaeth GL, Nowinski TS, et al.: Aniridia. A review. Surv Ophthalmol. 1984; 28(6): 621-42. PubMed Abstract | Publisher Full Text

4. Grant WM, Walton DS: Progressive changes in the angle in congenital aniridia, with development of glaucoma. Am J Ophthalmol. 1974; 78(5): 842-847. PubMed Abstract | Publisher Full Text

5. McCulley TJ, Mayer K, Dahr SS, et al:: Aniridia and optic nerve hypoplasia. Eye (Lond). 2005; 19(7): 762-764.

PubMed Abstract | Publisher Full Text

6. Nishida K, Kinoshita S, Ohashi $\mathrm{Y}$, et al:: Ocular surface abnormalities in aniridia. Am J Ophthalmol. 1995; 120(3): 368-375. PubMed Abstract | Publisher Full Text

7. Tsai JH, Freeman JM, Chan CC, et al:: A progressive anterior fibrosis syndrome in patients with postsurgical congenital aniridia. Am J Ophthalmol. 2005; 140(6): 1075-1079.

PubMed Abstract | Publisher Full Text

8. Thompson PJ, Mitchell TN, Free SL, et al.: Cognitive functioning in humans with mutations of the PAX6 gene. Neurology. 2004; 62(7): 1216-1218. PubMed Abstract | Publisher Full Text

9. Bamiou DE, Musiek FE, Sisodiya SM, et al.: Deficient auditory interhemispheric transfer in patients with PAX6 mutations. Ann Neurol. 2004; 56(4): 503-509. PubMed Abstract | Publisher Full Text

10. Bobilev AM, McDougal ME, Taylor WL, et al.: Assessment of PAX6 alleles in 66 families with aniridia. Clin Genet. 2016; 89(6): 669-77. PubMed Abstract | Publisher Full Text | Free Full Text
11. Hingorani M, Williamson KA, Moore AT, et al.: Detailed ophthalmologic evaluation of 43 individuals with PAX6 mutations. Invest Ophthalmol Vis Sci. 2009; 50(6): 2581-90.

PubMed Abstract | Publisher Full Text

12. Kim J, Lauderdale JD: Analysis of Pax6 expression using a BAC transgene reveals the presence of a paired-less isoform of Pax6 in the eye and olfactory bulb. Dev Biol. 2006; 292(2): 486-505. PubMed Abstract | Publisher Full Text

13. Manuel M, Price DJ: Role of Pax6 in forebrain regionalization. Brain Res Bull. 2005; 66(4-6): 387-393.

PubMed Abstract | Publisher Full Text

14. Simpson TI, Price DJ: Pax6; a pleiotropic player in development. Bioessays. 2002; 24(11): 1041-1051.

PubMed Abstract | Publisher Full Text

15. Mastick GS, Davis NM, Andrew GL, et al:: Pax-6 functions in boundary formation and axon guidance in the embryonic mouse forebrain. Development. 1997; 124(10): 1985-1997. PubMed Abstract

16. Osumi N: The role of Pax6 in brain patterning. Tohoku J Exp Med. 2001; 193(3) 163-174.

PubMed Abstract

17. Sisodiya SM, Free SL, Williamson KA, et al:: PAX6 haploinsufficiency causes cerebral malformation and olfactory dysfunction in humans. Nat Genet. 2001 28(3): 214-216. PubMed Abstract | Publisher Full Text

18. Mitchell TN, Free SL, Williamson KA, et al:: Polymicrogyria and absence of pineal gland due to PAX6 mutation. Ann Neurol. 2003; 53(5): 658-663. PubMed Abstract | Publisher Full Text

19. Bamiou DE, Free SL, Sisodiya SM, et al:: Auditory interhemispheric transfer deficits, hearing difficulties, and brain magnetic resonance imaging abnormalities in children with congenital aniridia due to PAX6 mutations. Arch Pediatr Adolesc Med. 2007; 161(5): 463-469. PubMed Abstract | Publisher Full Tex 
Abouzeid $\mathrm{H}$, Youssef MA, EIShakankiri N, et al.: PAX6 aniridia and interhemispheric brain anomalies. Mol Vis. 2009; 15: 2074-83. PubMed Abstract | Free Full Text

21. Free SL, Mitchell TN, Williamson KA, et al.: Quantitative MR image analysis in subjects with defects in the PAX6 gene. Neuroimage. 2003; 20(4): 2281-2290. PubMed Abstract | Publisher Full Text

22. Ellison-Wright Z, Heyman I, Frampton I, et al:: Heterozygous PAX6 mutation, adult brain structure and fronto-striato-thalamic function in a human family. Eur Neurosci. 2004; 19(6): 1505-12.

PubMed Abstract | Publisher Full Text

23. Yogarajah M, Matarin M, Vollmar C, et al:: PAX6, brain structure and function in human adults: advanced MRI in aniridia. Ann Clin TransI Neurol. 2016; 3(5): 314-30. PubMed Abstract | Publisher Full Text | Free Full Text

24. Pierce JE, Krafft CE, Rodrigue AL, et al.: Increased functional connectivity in intrinsic neural networks in individuals with aniridia. Front Hum Neurosci.
2014; 8: 1013

PubMed Abstract | Publisher Full Text | Free Full Text

25. Hanish AE, Butman JA, Thomas F, et al.: Pineal hypoplasia, reduced melatonin and sleep disturbance in patients with PAX6 haploinsufficiency. J Sleep Res. 2016; 25(1): 16-22.

PubMed Abstract | Publisher Full Text | Free Full Text

26. Wood $\mathrm{R}$, Bassett $\mathrm{K}$, Foerster $\mathrm{V}$, et al.: PROS AND CONS OF 1.5 T MRI VERSUS 3.0 T MRI.

Reference Source

27. Coffey CE, Lucke JF, Saxton JA, et al.: Sex differences in brain aging. a quantitative magnetic resonance imaging study. Arch Neurol. 1998; 55(2): 169-179.

PubMed Abstract | Publisher Full Text

28. Grant MK, Bobilev AM, Pierce JE, et al.: Dataset 1 in: Structural brain abnormalities in 12 persons with aniridia. F1000Research. 2017. Data Source 


\title{
Open Peer Review
}

\section{Current Peer Review Status:}

\section{Version 1}

Reviewer Report 18 April 2017

https://doi.org/10.5256/f1000research.11931.r21372

(C) 2017 Jäncke $\mathbf{L}$. This is an open access peer review report distributed under the terms of the Creative Commons Attribution License, which permits unrestricted use, distribution, and reproduction in any medium, provided the original work is properly cited.

\author{
Lutz Jäncke \\ Department of Psychology (Neuropsychology) and INAPIC, University of Zurich, Zurich, \\ Switzerland
}

This is an interesting and extremely important study reporting specific neuroanatomical features in patient group suffering from a rare disease affecting the visual system: aniridia. I have listed my comments and suggestions below.

\section{Introduction}

The introduction is fine and discusses the current literature. However, I would suggest to improve a bit the study question. The study question as it is used in the current version is very broad and does not come to the point (e.g.,"The current study sought to investigate gross anatomical correlates of aniridia in a new population sample. Results from this study will serve as a comparison for previous studies, as well as contribute to what is known about the distribution of neuroanatomical phenotypes in the aniridia population as a whole."). I would suggest to include a few statements what this new study will add to the literature and what the "problems" of the older studies are? In addition, it could be helpful for the reader to learn the very new and maybe innovative aspects of this study.

\section{Methods}

Subjects: Some additional information about the subjects could be helpful (cognitive ability, handedness, language lateralization). Some of these variables have been shown to be strongly related to the anatomical measures for which the authors are reporting the specific aniridia features.

Statistics: It is not entirely clear how the authors did their between-group comparisons. Did they compare the patients only on a visual-descriptive basis or did they perform a statistical analysis (which I would suggest). When doing a statistical analysis, one could compare single subjects to the mean of the control group. Thus, it would be possible to test each patient against the mean of the healthy control group. Using this comparison it would also be possible to calculate effect size measures for each subject. 
By the way, did the use a priorly defined regions of interest?

\section{Discussion}

The discussion is fine.

Is the work clearly and accurately presented and does it cite the current literature? Yes

Is the study design appropriate and is the work technically sound?

Yes

Are sufficient details of methods and analysis provided to allow replication by others? No

If applicable, is the statistical analysis and its interpretation appropriate?

Partly

Are all the source data underlying the results available to ensure full reproducibility? Yes

Are the conclusions drawn adequately supported by the results? Yes

Competing Interests: No competing interests were disclosed.

I confirm that I have read this submission and believe that I have an appropriate level of expertise to confirm that it is of an acceptable scientific standard, however I have significant reservations, as outlined above.

Author Response 23 Aug 2017

Madison Grant, University of Georgia, Athens, USA

Dr. Lutz Jäncke, Department of Psychology (Neuropsychology) and INAPIC, University of Zurich, Zurich, Switzerland

We thank Dr. Jäncke for the helpful comments and suggestions, which improved the manuscript. Our responses are listed below.

Introduction

Improve study question

Introduction has been revised to improve, clarify, and expand the description of our study question.

Suggest: to include a few statements what this new study will add to the literature 
and what the "problems" of the older studies are? In addition, it could be helpful for the reader to learn the very new and maybe innovative aspects of this study.

Introduction has been revised to include more information on new aspects for this study. In particular we have emphasized at the end of the "Introduction" section that this study utilized a 3T magnet instead of a 1.5T, allowing for higher resolution when examining small structures such as the anterior and posterior commissure. Additionally, we also clarified, at the end of the " Introduction" section, that our study examined five structures shown to be abnormal in the aniridia population. Previous studies focused on only a subset of structures in each patient rather than all five. By examining all five structures in a new population of aniridia patients, we have added to the collective knowledge on structural brain abnormalities present within the disorder.

\section{Methods}

Subjects: additional information: cognitive ability, handedness, language lateralization

We added handedness and predicted protein effect to Table 1. We do not have data on cognitive ability or language lateralization for our participants.

Statistics: It is not entirely clear how the authors did their between-group comparisons. Did they compare the patients only on a visual-descriptive basis or did they perform a statistical analysis (which I would suggest). When doing a statistical analysis, one could compare single subjects to the mean of the control group. Thus, it would be possible to test each patient against the mean of the healthy control group. Using this comparison it would also be possible to calculate effect size measures for each subject.

For this study, the structural changes in Table 1 were concluded by two independent reviews of the MRI scans using a visual-descriptive basis. The methods have been updated to clarify the visual-descriptive assessment.

Volumetric analysis was conducted for the corpus callosum using Freesurfer software and results have been added to the manuscript (see supplementary Table 1 and supplementary Figure 1). Findings from this volumetric analysis confirmed our structural examination of the corpus callosum for all subjects. We did not conduct quantitative volumetric analyses on the anterior and posterior commissures as these are relatively small structures and the plane of view was not consistent within all subjects. This is due to variation in slice location within each brain. Because of this we decided to rely on our visualdescriptive assessment of these two structures for our dataset. While not ideal, a visual-descriptive assessment of the anterior and posterior commissures is consistent with previous reports comparing these structures between PAX6 normal individuals and individuals with PAX6 mutations (e.g. Sisodiya et al. 
2001; Abouzeid et al., 2009) and captures relative changes between these two groups.

By the way, did the use a priorly defined regions of interest?

Yes, our Methods section (MRI data analysis) has been revised to state how we determined regions of interest. We used literature review to define which structures would be examined, and had ourthe radiologist (JD) examined the MRI scans for identification of additional regions of interest.

Discussion

The discussion is fine.

Competing Interests: No competing interests were disclosed.

Reviewer Response ( ) 17 Sep 2017

Lutz Jäncke, University of Zurich, Zurich, Switzerland

Thank you so much. Well done!

Competing Interests: No competing interests were disclosed.

Reviewer Report 06 April 2017

https://doi.org/10.5256/f1000research.11931.r21598

(C) 2017 van Heyningen V. This is an open access peer review report distributed under the terms of the Creative Commons Attribution License, which permits unrestricted use, distribution, and reproduction in any medium, provided the original work is properly cited.

\section{Veronica van Heyningen}

Institute of Ophthalmology, University College London, London, UK

This is an interesting report on structural brain changes in 12 aniridia patients examined by structural MRI studies, using 12 selected matching controls for comparison. The title and abstract convey details appropriately.

I should say at the outset that I have no expertise in MRI methodology and cannot compare the techniques used here with those used elsewhere, including our own papers.

It is clear, however, that MRI has advanced technically to a significant extent since the first set of papers was published in 2001-3. We need to know how directly comparable the results are. Certainly Sisodiya et al. in 2001 (ref 17) Mitchell et al. and 2003 (ref 18) used voxel-based morphometry and less powerful MRI measurements but showed similar findings with observed reduction or absence of the anterior commissure and olfactory bulb (ref 17) and of the pineal (ref 18). The current study does not mention study of the olfactory bulb. Interestingly olfactory 
function was also shown to be reduced and very occasionally absent in the first study (ref 17). Reduced interhemispheric transfer is thought to underlie the observed auditory processing problems reported in children with aniridia in ref 19 . The current study reported in this paper does not undertake functional smell or auditory tests. Although what seems to be the same cohort, judging by the reported mutations, has been studied by functional fMRI by Pierce et al (ref 24). Surprisingly this overlapping author group (with the current paper) reports an apparently increased functional connectivity in the patients studied in the current paper. The earlier studies by other groups do not look at these functional connectivity changes. It is regrettable that the later studies, including Yogarajah et al (ref 23) did not follow this up.

Otherwise the major findings are remarkably similar for this study and the previous studies to explore 12 or more cases. The controls in ref 17 and 18 are larger numbers (100) and not directly paired controls. The study in Ref 20 where the posterior commissure reduction was observed, only looked at the index case from three families with aniridia and PAX6 mutations. Reference 23 reexamines many of the same cases as Ref 17 and 18, but about a decade later and with more powerful MRI using surface-based morphometry. The reduced cortical measurements are more obvious in these older cases. The observed reduction of the optic chiasm reported here in 7/12 cases is an interesting new finding, first suggested in the one of the three families studied by Abouzeid et al, ref 20.

Minor comments

1. In the Introduction the PAX6 mutations are described as mostly "single nucleotide polymorphisms". This is incorrect the changes are extremely rare variants. There are no polymorphisms of any note in the extremely highly conserved PAX6 gene.

2. It is a pity that the patient numbering is different in earlier fMRI work from this group (ref 24). Indeed it is not made clear that ref 24 studies the same cohort as observed in the current paper.

3. It would help to have the protein effects of the mutations in Table 1.

4. Can the olfactory bulb status be observed with the current cohort? It would be interesting to see that reported.

Is the work clearly and accurately presented and does it cite the current literature? Yes

Is the study design appropriate and is the work technically sound? Yes

Are sufficient details of methods and analysis provided to allow replication by others? Yes

If applicable, is the statistical analysis and its interpretation appropriate? Yes

Are all the source data underlying the results available to ensure full reproducibility? 
Yes

Are the conclusions drawn adequately supported by the results?

Yes

Competing Interests: I am a co-author on several of the cited references, in particular several reporting results of similar studies (refs 17, 18, 19, 23 and some others.

I confirm that I have read this submission and believe that I have an appropriate level of expertise to confirm that it is of an acceptable scientific standard.

Author Response 23 Aug 2017

Madison Grant, University of Georgia, Athens, USA

Reviewer: Veronica van Heyningen, Institute of Ophthalmology, University College London, London, UK

We thank Dr. van Heyningen for the helpful comments and suggestions, which improved the manuscript. Our responses are listed below.

Comments to the Author:

Minor comments

1. In the Introduction the PAX6 mutations are described as mostly "single nucleotide polymorphisms". This is incorrect the changes are extremely rare variants. There are no polymorphisms of any note in the extremely highly conserved PAX6 gene.

- The text was modified to read: "The majority of these variants are nonsense mutations, which lead to a premature termination codon, and are found across the PAX6 locus."

2. It is a pity that the patient numbering is different in earlier fMRI work from this group (ref 24). Indeed it is not made clear that ref 24 studies the same cohort as observed in the current paper.

- Numbering of patients has been amended to reflect the same numbering used in the previous paper (ref 24). We have additionally added a supplementary table (Supplementary Table 2) that matches DICOM file names to patient ID from this paper and previous papers using the same patient group. Additionally, we have added a sentence in methods (Subjects) to state that this study and ref 24 used the same patients.

3. It would help to have the protein effects of the mutations in Table 1.

- Protein effects have been added to Table 1.

4. Can the olfactory bulb status be observed with the current cohort? It would be 
interesting to see that reported.

- While we agree that the olfactory bulb would be an interesting and important addition, we elected not to pursue this structure because constraints inherent to our data. We have amended methods (MRI data analysis) to discuss explain why we decided not to investigate olfactory bulb in this patient sample.

Competing Interests: No competing interests were disclosed.

The benefits of publishing with F1000Research:

- Your article is published within days, with no editorial bias

- You can publish traditional articles, null/negative results, case reports, data notes and more

- The peer review process is transparent and collaborative

- Your article is indexed in PubMed after passing peer review

- Dedicated customer support at every stage

For pre-submission enquiries, contact research@f1000.com 